\title{
Analytic Measures for Adaptability of Wheat Genotypes for Northern Hills Zone of Country by Mixed Model Approach
}

\author{
Ajay Verma*, R. Chatrath and G. P. Singh
}

Division of Crop Improvement, ICAR-Indian Institute of Wheat \& Barley Research, Post Bag \# 158 Agrasain Marg, Karnal 132001 (Haryana), India

*Corresponding author

\section{A B S T R A C T}

\section{Keywords}

BLUE, BLUP, Mixed Models, PRVG, MHVG, MHPRVG

Article Info

Accepted: 04 September 2019 Available Online: 10 October 2019

\begin{abstract}
Adaptability of wheat genotypes studied by mixed model methodology under rainfed sown trials for the Northern Hills Zone of the country. Analytic measures marked HS612, HPW430, VL2023 \& HS507 as of high yield and better adaptability across major locations of this zone while HS615 \& HS617 for low degree of adaptation as per year 2015-16. Biplot analysis expressed stable yield of HPW349 and HPW441 genotypes. Majhera, Ranichauri and Khudwani, would be suitable environments for stable yield of genotypes. HPW442 had specific adaptations to Dhaulakuan and Berthin while HP441 for Almora and VL907 for Malan and Ranichauri, whereas HPW349 and HS634 identified for Khudwani. Genotypes HS631, HS632, VL2030 \& VL 2025 were of high yield and better adaptability across major locations of this zone while HS 635 \& VL 2028 with lower level of adaptation during 2016-17. Biplot analysis considered 86.1\% of total GxE interaction sum of squares marked HS507, HS634, HS636 and UP2991 genotypes of stable yield. HPW447 had specific adaptations to Wadhura, and Khudwani while VL2030 \& VL2025 for Almora, whereas VL2027, UP2990 \& VL2028 identified for Bajaura. Third year of study 2017-18 identified HS562 \& VL907 with yield and better adaptability. Biplot analysis observed UP2953, HPW428 and HS613 as desirable genotypes for yield and adaptability. VL2021, HS616, HS507, HPW425 and HPW426 had specific adaptations to Shimla and VL2020, VL2024, HS613 would be for Almora and Malan, whereas HPW426 identified for Khudwani. Analytic measures based on Harmonic means showed suitability to identify the better adaptive genotypes with high yield.
\end{abstract}

\section{Introduction}

Knowledge about the genotype-byenvironments interaction (GxE) effects is necessary for efficient plant breeding strategies (Burgueño et al., 2007). One of main challenges faced by Indian farmers is the wide yield variation caused by environmental conditions i.e. related to climate and soils quality that affects the crop performance (Crespo et al., 2017). These factors may cause low genotypic adaptability which is very common in quantitative traits viz., yield. The expected marginal means obtained across several environmental are calculated to drop out the environmental nuisance factors 
(Crossa et al., 2006). Evaluation of genotypes under multi-environment trials (METs) is exploited in breeding programs to study the stability and adaptability of genotypes along with performance prediction in different environments (Oliveira et al., 2017).

GxE may be understood as the phenomenon where the genotypes show different responses across the environments cause to it the ranking of genotypes altered in the target environments (Nuvunga et al., 2018). Quite large number of methods has been cited in literature to predict yield in different locations (Silveira et al., 2018). Among the statistical methods used for MET analysis mixed models approach based on factor analysis or FA structure has been very well appreciated as allows genotypes and $\mathrm{GxE}$ interactions as random effects and environment is fixed (Kelly et al., 2007; Burgueño et al., 2011; Friesen et al., 2016; Nuvunga et al., 2018). FA method has offered advantages as compared to traditional analysis methods in the plant breeding (Piepho et al., 2008; Meyer, 2009; Smith \& Cullis, 2018).

\section{Materials and Methods}

Wheat is cultivated in the hills at different altitudes suited to fit under different crop rotations as per specific adaptations at different elevations. In general sowing is done for Northern Hills Zone under rainfed conditions in October/November with residual moisture and harvesting takes place in May/June. Development of high yielding varieties for moisture stress condition is the major objective of wheat improvement programmes in NHZ. Region encompasses the hilly terrain of Northern region extending from Jammu \& Kashmir to North Eastern States. NHZ comprises J\&K (except Jammu and Kathua distt.); Himachal Pradesh (except Una and Paonta Valley); Uttarakhand (except Tarai area); Sikkim, hills of West Bengal and North Eastern states. Advanced wheat genotypes were evaluated in field trials at major locations of the zone during cropping season's viz. 2015-16, 2016-17 and 2017-18 as details are reflected in tables $1,2 \& 3$ for ready reference. Randomized block design with three replications were used for research field trials and recommended agronomical practices had followed to harvest good crop. More over grain yield were further analysed as per recent analytic adaptability measures (Fig. $1)$.

The yield of $g$ genotypes evaluated at $\mathrm{e}$ environments with $r$ replications can be modeled as follows (Hernandez et al., 2019):

$$
Y=X b+Z_{r} r+Z_{g} g+e
$$

where $X$ is the incidence matrix for the fixed effects of environments and $Z_{\mathrm{r}} \& \mathrm{Z}_{\mathrm{g}}$ are the incidence matrices for the random effects of replicates within sites and genotypes within sites that combine the main effects of genotypes and GxE interaction. Vector $b$ denotes fixed effect of environments and vectors $\mathrm{r}, \mathrm{g}$ and $\mathrm{e}$ are the random effect of replicates within environments, genotypes within environments and residuals within environments, respectively. These effects are assumed to be random and normally distributed with zero mean vectors and variance - covariance matrices $R, G, E$ respectively, such that the joint distribution of $\mathrm{r}, \mathrm{g}$ and e is multivariate normal (Crossa et al., $2004 \& 2006)$

The variance-covariance matrices $\mathrm{R}$ and $\mathrm{E}$ are $\mathrm{R}=\Sigma_{\mathrm{r}} \otimes \mathrm{I}_{\mathrm{r}}$ and $\mathrm{E}=\Sigma_{\mathrm{e}} \otimes \mathrm{I}_{\mathrm{rg}}$, where $\mathrm{I}_{\mathrm{r}}$ and $\mathrm{I}_{\mathrm{rg}}$ are the identity matrices of order $r$ and $r \times g$, respectively, $\Sigma_{\mathrm{r}}=\operatorname{diag}\left(\sigma_{r j}^{2}, j=1,2, \ldots, e\right)$ and $\Sigma_{\mathrm{e}}=\operatorname{diag}\left(\sigma_{e j}^{2}, j=1,2, \ldots, e\right) ; \sigma_{r j}^{2}, \sigma_{e j}^{2}$ are the replicate and residual variances within the $j$ th environment, respectively, and $\otimes$ is the Kronecker (or direct) product of the two matrices. 
The factor analytic structure for $\mathrm{G}$ in terms of a few unobservable factors can be expressed as $\sum_{k=1}^{t} \delta_{i k} X_{\mathrm{jk}}+\mathrm{d}_{\mathrm{ij}}$, where $\delta_{\mathrm{ik}}$ is the $k \mathrm{th}$ random regression coefficient of the $i$ th genotype (loading or genotypic sensitivity) to the $k$ th unobserved (latent) variable related to the $j$ th environment (environmental potentiality), $X_{j k}$ and $d_{i j}$ is the residual interaction term. In matrix notation, the vector of genotypic effects is represented by $g=\Delta x$ $+\mathrm{d}$ so that the variance-covariance of $\mathrm{g}$ is $\mathrm{V}(\mathrm{g})=\Delta \mathrm{V}(\mathrm{x}) \Delta^{\prime}+\mathrm{D}$ and, since $\mathrm{V}(\mathrm{x})=\mathrm{I}$, $\mathrm{V}(\mathrm{g})=\Delta \Delta^{\prime}+\mathrm{D}$. The factor analytic model implies that the variance of the effect of $i$ th genotype is $\sum_{k=1}^{t} \delta_{j k}{ }^{2}+\mathrm{d}_{\mathrm{i}}$ and the covariance of the effects of genotypes $i$ and i' is $\sum_{k=1}^{t} \delta_{i k} \delta_{i k}$.

Simple and effective measure for adaptability is based on the relative performance of genetic values (PRVG) across environments. Resende (2007) considered the yield \& stability, described the MHVG method (harmonic mean of genetic values) and based on the harmonic mean of the genotypic values. The lower the standard deviation of genotypic performance across environments, the greater is the harmonic mean of genotypes. For the use of mixed models, Resende (2007) proposed the simultaneous analysis of stability, adaptability and yield based on the harmonic mean of the relative performance of the genotypic values (MHPRVG). The MHPRVG combines the methods PRVG and MHVG, simultaneously. Consequently, the selection for higher values of the harmonic mean results in selection for both yield and stability.

$\mathrm{PRVG}_{\mathrm{ij}}=\mathrm{VG}_{\mathrm{ij}} / \mathrm{VG}_{\mathrm{i}}$

$\mathrm{MHVG}_{\mathrm{i}}=$ Number of environments $/ \sum_{i=1}^{k} \frac{1}{x_{i}}$

MHPRVG $_{\mathrm{i}}$ = Number of environments / $\sum_{j=1}^{k} \frac{1}{P R V G_{i j}}$
$\mathrm{VG}_{\mathrm{ij}}$ is the genotypic value of the $\mathrm{i}$ genotype, in the $\mathrm{j}$ environment, expressed as a proportion of the average in this environment. PRVG and MHPRVG values were multiplied by the general mean (GM) to have results in the same magnitude as of the average wheat yield in order to facilitate interpretation (Verardi et al., 2009). Estimation of the variance components were carried out by ASReml-R package using residual maximum likelihood (REML) along with estimation / prediction of the fixed as well as random effects (Smith and Cullis, 2018).

\section{Results and Discussion}

\section{First year (2015-16)}

Average yield of genotypes as per BLUPs identified HS612, HS507, HPW430 and VL2021 of better adaptations along with high yield while HS615 \& UP2952 expressed low yield. Ranking of genotypes based on harmonic mean of BLUP's selected HS612, HPW430 VL2024 \& VL2023 as better adapted genotypes at the same time pointed out suitability of HS615 \& HS617 for specific adaptations (Table 4). Average of genotypes based on BLUE's pointed towards HS612, HPW430, HS507 and VL2021 as desirable genotypes whereas as Harmonic mean observed advantages for HS612, HPW430, VL2024 and VL2020. Adaptability measures

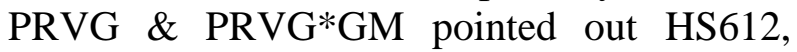
HPW430, HS507 and VL2023 for the better adaptable behavior and HS615 \& HS617 of low adaptability under rainfed timely sown conditions for Northern Hills Zone.

Analytic measures HMPRVG and HMPRVG*GM marked HS612, HPW430, VL2023 \& HS507 as of high yield and better adaptability across major locations of this zone while HS615 \& HS617 for low degree of adaptation. Consensus has been observed among analytic measures PRVG, MHVG, 
MHPRVG and HM-UP for the classification of wheat genotypes (Table 4).

Only marginal variation in average yield of wheat genotypes had been observed as per BLUP and BLUE across locations of zone for rainfed timely sown conditions (Figure 2). Relatively comparable yield of genotypes were estimated as per Best Linear Unbiased predictors except for HS612 \& HPW430. Moreover, the heights of standard error of genotypes were more or less same under fixed and random effects of genotypes.

Genotypes or environments located near the origin of the coordinate system in the Biplot presentations were considered stable; however, the more distant from the source the lower the stability of the wheat yield; these effects are due to the nature of the $\mathrm{G} \times \mathrm{E}$ interaction. A genotype is considered adapted to a particular environment when it is situated in the same quadrant of the environment (Yan and Kang, 2003). Biplot analysis based on first two highly significant Interaction Principal Components expressed stable yield of HPW349 and HPW441 genotypes. HS507, HS562, HS634 and VL907 would be good genotypes for specific adaptations. These two significant interaction principal components, accounted for $90.3 \%$ of total GxE interaction sum of squares (Figure 5). Majhera, Ranichauri and Khudwani, would be suitable environments for stable yield of genotypes. Environments Bajura, Malan and Dhaulakuan observed as larger contributor to the $\mathrm{G} \times \mathrm{E}$ interactions, because as positioned relatively away from the origin.

Genotypes and environments placed in proximity have positive associations as these observations would enable to identify specific adaptations of the genotypes. HPW442 had specific adaptations to Dhaulakuan and Berthin while HP441 for Almora and VL907 for Malan and Ranichauri, whereas HPW349 and HS634 identified for Khudwani. Berthin with Dhaulakuan, Ranichauri with Malan, Majhera with Arkot would show similar performance of genotypes as expressed acute angles among rays connecting these environments. Malan had an obtuse angle with Khudwani this would express opposite performance of genotypes i.e. HPW349 will not be of choice for Malan.

\section{Second year (2016-17)}

Mean yield of genotypes based on BLUPs pointed towards HPW447, HS631, HS632 \& VL2030 of better adaptations along with high yield while HS635 \& HS637 expressed low yield. Ranking of genotypes based on harmonic mean of BLUP's selected HS631, HS632, VL2030 \& VL2025 as better adapted genotypes at the same time pointed out suitability of HS 635 \& VL2028 for specific adaptations (Table 5). Mean yield of genotypes as per BLUE's identified HS631, HPW447, HS632 \& VL2030 as desirable genotypes whereas as Harmonic mean observed advantages for HS631, HS632, VL2030 \& VL2025. PRVG as well as by PRVG*GM pointed out HS631, HS632, HPW447 \& VL2030 for the better adaptable behavior and HS635 \& VL2028 of low adaptability for Northern Hills Zone. Recent measures of adaptability HMPRVG and HMPRVG*GM marked HS631, HS632, VL2030 \& VL2025 of high yield and better adaptability across major locations of this zone while HS635 \& VL2028 as for low degree of adaptation. Consensus has been observed among analytic measures PRVG, MHVG, MHPRVG, and HM-UP for the classification of wheat genotypes (Table 6).

Variation in average yield of wheat genotypes had been observed as per BLUP and BLUE across locations of zone (Figure 3). Relatively higher yield of genotypes were estimated as per Best Linear Unbiased Estimators except 
for HPW444 \& HS637. Moreover, the heights of standard error of genotypes were more under fixed effects of genotypes.

Biplot analysis based on first two highly significant Interaction Principal Components expressed stable yield of HS507, HS634, HS636 and UP2991 genotypes. HPW447, VL2028 and HS637 would be good for specific adaptations. First two significant interaction principal components contributed $86.1 \%$ to total $\mathrm{GxE}$ interaction sum of squares (Figure 6). Malan and Bajaura would be suitable environments for stable yield of genotypes. Environments Shimla, Wadhua and Khudwani positioned relatively away from the origin.

Genotypes and environments placed in proximity have positive associations enable to identify specific adaptations. HPW447 had specific adaptations to Wadhura, and Khudwani while VL2030 \& VL2025 for Almora, whereas VL2027, UP2990 \& VL2028 identified for Bajaura. Malan with Almora and Bajaura whereas Wadura with Khudwani would show similar performance of genotypes as expressed acute angles among rays connecting these environments. Shimla had an obtuse angle with Wadura this would express opposite performance of genotypes i.e. HPW447 will not be of choice for Shimla.

\section{Third year (2017-18)}

Mean yield of genotypes by considering BLUP values identified HS562 \& HPW442 of better adaptations along with high yield while HS507 expressed low yield. Ranking of genotypes based on harmonic mean of BLUP's selected VL907 \& HS562 as better adapted genotypes at the same time pointed out suitability of HS634 for specific adaptations (Table 6). Average of genotypes based on BLUE's pointed towards HS562 \& HPW441 as desirable genotypes whereas as
Harmonic mean observed advantages for VL907 \& HS562. PRVG as well as by PRVG*GM pointed out HS562 \& VL907 for the better adaptable behavior and HS634 of low adaptability under rainfed conditions of Northern Hills Zone. Most cited analytic measures HMPRVG and HMPRVG*GM marked HS562 \& VL907 of high yield and better adaptability across major locations of this zone while HS634 as for low degree of adaptation. Analytic measures PRVG, MHVG, MHPRVG, and HM-UP showed consensus for the classification of wheat genotypes (Table 6).

Marginal variation in average yield of wheat genotypes had been observed as per BLUP and BLUE across locations of zone for rainfed sown conditions (Figure 4). Relatively more yield of genotypes was estimated as per Best Linear Unbiased Estimators except for HS634 \& HPW441. Moreover, the heights of standard error of genotypes were more under fixed effects of genotypes.

Biplot analysis based on first two highly significant Interaction Principal Components observed stable yield of genotypes UP2953, HPW428 and HS613. Genotypes HS612, HS615 and HPW427 would be good for specific adaptations. These two significant interaction principal components, accounted for $84.4 \%$ of total $\mathrm{GxE}$ interaction sum of squares (Figure 7). Shimla and Malan would be suitable environments for stable yield of genotypes. Environments Almora and Khudwani positioned relatively away from the origin.

Genotypes and environments placed in proximity would have positive associations. VL2021, HS616, HS507, HPW425 and HPW426 had specific adaptations to Shimla and VL2020, VL2024, HS613 would be for Almora and Malan, whereas HPW426 identified for Khudwani. 
Table.1 Parentage and location details under multi environmental trials (2015-16)

\begin{tabular}{|c|c|c|c|c|c|}
\hline Genotype & Parentage & Locations & Latitude & $\begin{array}{l}\text { Longi } \\
\text { tude }\end{array}$ & $\begin{array}{l}\text { Altit } \\
\text { ude }\end{array}$ \\
\hline HPW 425 & (VL832/WH423) & Almora & $29^{\circ} 35^{\prime} \mathrm{N}$ & $\begin{array}{l}79^{\circ} \\
39^{\prime} \mathrm{E}\end{array}$ & 1610 \\
\hline VL2022 & (EC635640) & Khudwani & $33^{\circ} 70^{\prime} \mathrm{N}$ & $\begin{array}{l}75^{\circ} 10^{\prime} \\
\mathrm{E}\end{array}$ & 1590 \\
\hline VL2019 & $\begin{array}{l}\text { (RWP2002- } \\
\text { 2/SW89.3218//AGRI/NAC//VL905) }\end{array}$ & Malan & $32^{\circ} 08^{\prime} \mathrm{N}$ & $\begin{array}{l}76^{\circ} 35^{\prime} \\
\mathrm{E}\end{array}$ & 846 \\
\hline HPW431 & (HPW42/HPW236) & Shimla & $31^{\circ} 10^{\prime} \mathrm{N}$ & $\begin{array}{l}77^{\circ} 17^{\prime} \\
\mathrm{E}\end{array}$ & 2276 \\
\hline HPW430 & (HPW249/HPW211) & & & & \\
\hline UP2953 & $\begin{array}{l}\text { (WBLL1/KUKUNA//TACUPETO } \\
\text { F2001/3/KIRITATI) }\end{array}$ & & & & \\
\hline VL2024 & $\begin{array}{l}\text { (W15.92/4/PASTOR//HXL7573/2*BAU/3/W } \\
\text { BLL1/5/MUNAL) }\end{array}$ & & & & \\
\hline VL2023 & $\begin{array}{l}\text { (ATTILA/3/WEAVER*2/TSC//WEAVER/4/ } \\
\text { ATTILA/PASTOR) }\end{array}$ & & & & \\
\hline HPW427 & (VL616/FLW3) & & & & \\
\hline HS616 & (SOKOLL/3/PASTOR//HXL7573/2*BAU) & & & & \\
\hline HS612 & $\begin{array}{l}\text { (SERI.1B*2/3KAUZ*2/BOW//KAUZ*2/5/C } \\
\text { NO79/PF70354/MUS/3/PASTOR/4/BAV92) }\end{array}$ & & & & \\
\hline HPW429 & (ESWYT(2008)115/HPW211) & & & & \\
\hline HS507@ & (KAUZ/MYNA/VUL//BUC/FLK/4/MILAN) & & & & \\
\hline HPW426 & (HPW155/HD29) & & & & \\
\hline UP2952 & (MILAN/S87230//BAV92*2/3/AKURI) & & & & \\
\hline HS615 & (BERKUT/HTG) & & & & \\
\hline HPW428 & (HPW155/HD29) & & & & \\
\hline HS613 & (WBM1587/VL824) & & & & \\
\hline HS614 & (HPW155/CHINESE LINE 14) & & & & \\
\hline HS617 & $\begin{array}{l}\text { (PASTOR/3/CROC- } \\
\text { 1/AE.SQUARROSA(224)//OPATA/4/BERK } \\
\text { UT) }\end{array}$ & & & & \\
\hline VL907@) & $\begin{array}{llll}(\mathrm{DYBR} & 1982-83 / 842 & \text { ABVD } & 50 / \mathrm{VW} \\
9365 / / \mathrm{PBW} 343 & & \end{array}$ & & & & \\
\hline VL2020 & $\begin{array}{l}\text { (KLEIBER/2*FL80/DONSK.POLL/AKAW4 } \\
\text { 006) }\end{array}$ & & & & \\
\hline VL2021 & $\begin{array}{l}\text { (KLEIBER/2*FL80/DONSK.POLL/GW2000 } \\
-18)\end{array}$ & & & & \\
\hline HS618 & (BERKUT/HTG) & & & & \\
\hline
\end{tabular}


Table.2 Parentage and location details under multi environmental trials (2016-17)

\begin{tabular}{|c|c|c|c|c|c|}
\hline Genotype & Parentage & Locations & Latitude & Longitude & Altitude \\
\hline HS 631 & (WHEAR/VIVITSI//WHEAR) & Almora & $29^{\circ} 35^{\prime} \mathrm{N}$ & $79^{\circ} 39^{\prime} \mathrm{E}$ & 1610 \\
\hline HS 632 & (HS240*2/FLW20(LR19)//HS240*2/FLW13(YR15) & Bajaura & $31^{\circ} 84^{\prime} \mathrm{N}$ & $77^{\circ} 16^{\prime} \mathrm{E}$ & 1099 \\
\hline HS 633 & (HS240*2/FLW20(LR19)//HS240*2/FLW13(YR15) & Khudwani & $33^{\circ} 70^{\prime} \mathrm{N}$ & $75^{\circ} 10^{\prime} \mathrm{E}$ & 1590 \\
\hline HS 634 & (PBW343*2/KUKUNA/5/CNO79//PF73054/MUS/3/PASTOR/4/BAV92) & Malan & $32^{\circ} 08^{\prime} \mathrm{N}$ & $76^{\circ} 35^{\prime} \mathrm{E}$ & 846 \\
\hline HS 635 & (PFAU/MILAN/5/CHEN/AE.SQUARROSA(TAUS)//BCN/3/VEE\#7/BOW/4/PASTOR) & Shimla & $31^{\circ} 10^{\prime} \mathrm{N}$ & $77^{\circ} 17^{\prime} \mathrm{E}$ & 2276 \\
\hline HS 636 & $\begin{array}{l}\text { (PASTOR//KAUZ/6/CNDO/R143//ENTE/MEX1- } \\
\text { 2/3/AEGILOPSSQUARROSA(TAUS)/4/WEAVER/5/2*KAUZ) }\end{array}$ & Wadura & $21^{\circ} 18^{\prime} \mathrm{N}$ & $77^{\circ} 41^{\prime} \mathrm{E}$ & 508 \\
\hline HS 637 & $(\mathrm{PRL} / 2 * \mathrm{PASTOR})$ & & & & \\
\hline HPW 441 & (NAC/TH.AC//3*MIRLO/BUC/4/PASTOR) & & & & \\
\hline HPW 442 & $(\mathrm{LONG} 291 * 2 / \mathrm{PASTOR})$ & & & & \\
\hline HPW 443 & (PASTOR//HXL7573/2*BAU/3/SOKOLL/WBLL1) & & & & \\
\hline HPW 444 & (AZAR2/4/CROC_1/AE.SQUARROSA (205)//BORL95/3/2*MILAN/5/BERKUT) & & & & \\
\hline HPW 445 & (PBW575/HPW251) & & & & \\
\hline HPW 446 & (BOW/URES//KEA/3/SITE) & & & & \\
\hline HPW 447 & (HPW266/HPW249) & & & & \\
\hline VL 2025 & (LBPY04-1/RAJ4132//HS490) & & & & \\
\hline VL 2026 & (GW366/KS82W428/SWM75740//UP2739) & & & & \\
\hline VL 2027 & (RAJ4083/SKAUZ/HATUSA/VL900) & & & & \\
\hline VL 2028 & (FRANCOLIN\#1*2/MUU) & & & & \\
\hline VL 2029 & (MUNAL\#1/FRANCOLIN\#1) & & & & \\
\hline VL 2030 & (KA/NAC//TRCH/3/DANPHE\#1) & & & & \\
\hline UP 2990 & (UP2744/WL711//PBW644) & & & & \\
\hline UP 2991 & (SOKOLL/3/PASTOR//HXL7573/2*BAU/4/SOKOLL/WBLL1) & & & & \\
\hline VL 907 & (DYBR1982-8384ABVD50/VW9365//PBW343) & & & & \\
\hline HS 507 & (KAUZ/MYNA/VUL//BUC/FLK/4/MILAN) & & & & \\
\hline
\end{tabular}


Table.3 Parentage and location details under multi environmental trials (2017-18)

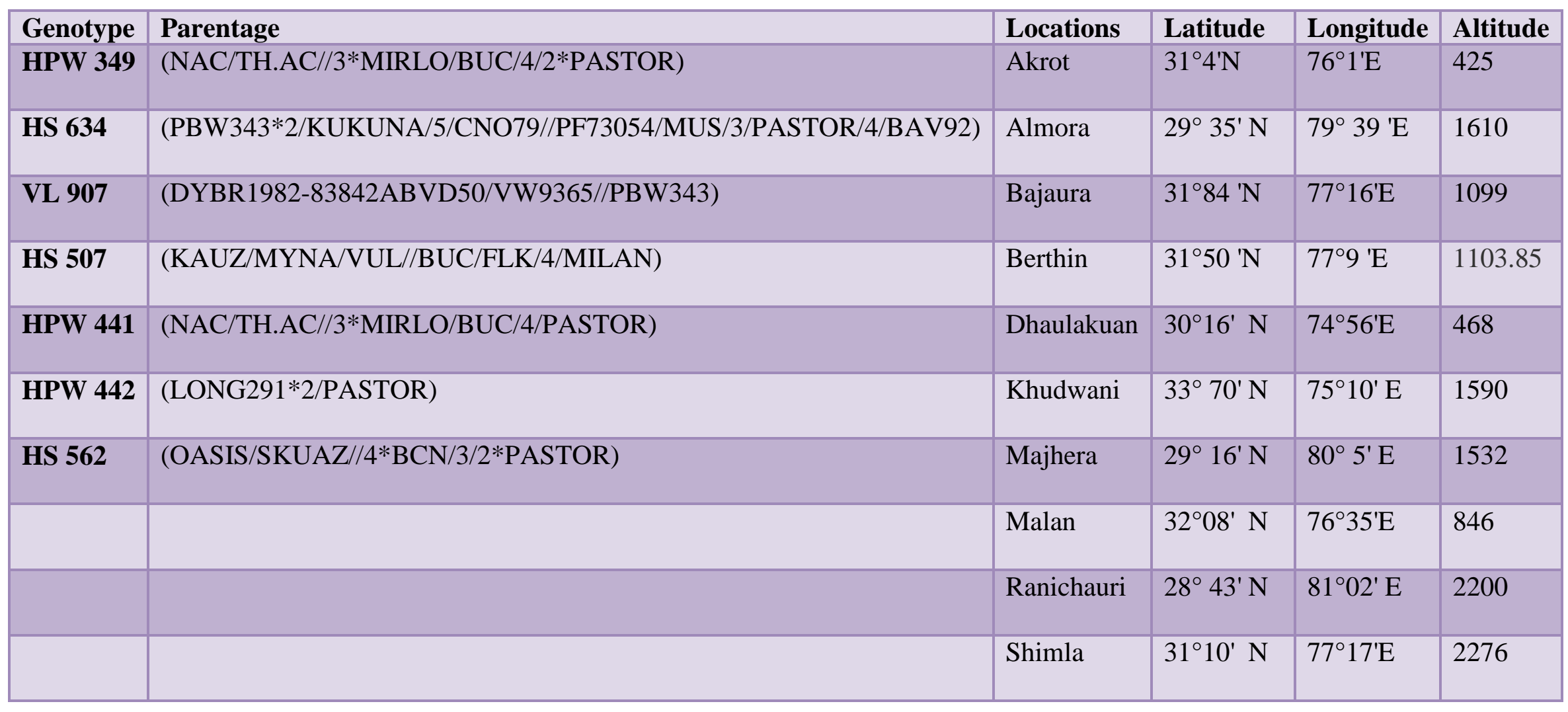


Table.4 Analytic measures of adaptability for wheat genotypes (2015-16)

\begin{tabular}{|c|c|c|c|c|c|c|c|c|c|c|c|c|c|c|c|c|}
\hline Genotype & BLUP & Rk & HM-UP & Rk & BLUE & $\mathbf{R k}$ & HM-UE & $\mathbf{R k}$ & PRVG & $\mathbf{R k}$ & PRVG*GM & $\mathbf{R k}$ & HPVRG & $\mathbf{R k}$ & HPVRG*GM & $\mathbf{R k}$ \\
\hline HPW 425 & 27.22 & 6 & 24.63 & 7 & 27.15 & 6 & 24.36 & 8 & 1.0737 & 7 & 26.90 & 7 & 1.0601 & 8 & 26.56 & 8 \\
\hline VL2019 & 23.76 & 16 & 23.67 & 10 & 23.85 & 16 & 23.79 & 10 & 0.9991 & 13 & 25.03 & 13 & 0.9599 & 16 & 24.05 & 16 \\
\hline HPW430 & 28.16 & 3 & 25.60 & 2 & 28.40 & 2 & 25.82 & 2 & 1.1078 & 2 & 27.76 & 2 & 1.1047 & 2 & 27.68 & 2 \\
\hline UP2953 & 25.74 & 12 & 22.24 & 16 & 25.68 & 13 & 21.83 & 16 & 0.9988 & 14 & 25.02 & 14 & 0.9688 & 14 & 24.28 & 14 \\
\hline VL2024 & 26.56 & 8 & 25.36 & 3 & 26.77 & 7 & 25.51 & 3 & 1.0777 & 6 & 27.00 & 6 & 1.0676 & 6 & 26.75 & 6 \\
\hline HS616 & 26.24 & 10 & 23.58 & 13 & 26.41 & 10 & 23.53 & 12 & 1.0303 & 11 & 25.81 & 11 & 1.0217 & 11 & 25.60 & 11 \\
\hline HS612 & 29.23 & 1 & 28.46 & 1 & 29.75 & 1 & 29.08 & 1 & 1.1991 & 1 & 30.04 & 1 & 1.1839 & 1 & 29.66 & 1 \\
\hline HPW429 & 24.57 & 15 & 23.66 & 11 & 24.67 & 15 & 23.74 & 11 & 1.0000 & 12 & 25.06 & 12 & 0.9924 & 12 & 24.87 & 12 \\
\hline HS507 & 28.28 & 2 & 24.93 & 6 & 28.25 & 3 & 24.80 & 6 & 1.0977 & 3 & 27.50 & 3 & 1.0805 & 4 & 27.07 & 4 \\
\hline HPW426 & 26.66 & 7 & 23.63 & 12 & 26.71 & 8 & 23.50 & 13 & 1.0387 & 9 & 26.03 & 9 & 1.0287 & 10 & 25.77 & 10 \\
\hline UP2952 & 21.11 & 23 & 20.93 & 19 & 20.91 & 23 & 20.76 & 19 & 0.8812 & 21 & 22.08 & 21 & 0.8558 & 22 & 21.44 & 22 \\
\hline HS617 & 21.21 & 22 & 20.04 & 23 & 21.01 & 22 & 19.73 & 22 & 0.8578 & 23 & 21.49 & 23 & 0.8474 & 23 & 21.23 & 23 \\
\hline VL907 & 23.56 & 17 & 23.33 & 14 & 23.61 & 17 & 23.42 & 14 & 0.9819 & 17 & 24.60 & 17 & 0.9557 & 17 & 23.95 & 17 \\
\hline VL2020 & 26.54 & 9 & 25.20 & 5 & 26.66 & 9 & 25.37 & 4 & 1.0685 & 8 & 26.77 & 8 & 1.0652 & 7 & 26.69 & 7 \\
\hline VL2021 & 27.86 & 4 & 24.62 & 8 & 28.25 & 4 & 24.60 & 7 & 1.0896 & 5 & 27.30 & 5 & 1.0710 & 5 & 26.83 & 5 \\
\hline HS618 & 25.16 & 14 & 22.78 & 15 & 25.21 & 14 & 22.68 & 15 & 0.9904 & 16 & 24.82 & 16 & 0.9844 & 13 & 24.67 & 13 \\
\hline
\end{tabular}

BLUP ( average of values); HM-UP (Harmonic mean of BLUP); MHVG( Harmonic mean of the genotypic values); PRVG(Relative performance of genotypic values); GM (Overall average); MHPRVG ( harmonic mean of the relative performance of the predicted genotypic values); Rk (rank of genotypes) 
Table.5 Analytic measures of adaptability for wheat genotypes (2016-17)

\begin{tabular}{|c|c|c|c|c|c|c|c|c|c|c|c|c|c|c|c|c|}
\hline Genotype & BLUP & $\mathbf{R k}$ & HM-UP & Rk & BLUE & $\mathbf{R k}$ & HM-UE & Rk & PRVG & Rk & PRVG*GM & $\mathbf{R k}$ & HPVRG & $\mathbf{R k}$ & HPVRG*GM & Rk \\
\hline HS 631 & 31.62 & 2 & 29.69 & 1 & 31.95 & 1 & 30.11 & 1 & 1.0789 & 1 & 31.55 & 1 & 1.0755 & 1 & 31.45 & 1 \\
\hline HS 633 & 29.07 & 13 & 26.97 & 13 & 30.19 & 6 & 28.33 & 6 & 0.9892 & 14 & 28.93 & 14 & 0.9832 & 15 & 28.75 & 15 \\
\hline HS 635 & 26.67 & 24 & 24.66 & 24 & 26.28 & 24 & 24.12 & 24 & 0.9074 & 24 & 26.53 & 24 & 0.8960 & 24 & 26.20 & 24 \\
\hline HS 636 & 28.89 & 14 & 27.25 & 11 & 29.02 & 12 & 27.48 & 13 & 0.9895 & 13 & 28.93 & 13 & 0.9843 & 13 & 28.78 & 13 \\
\hline HS 637 & 27.50 & 23 & 26.52 & 20 & 27.13 & 23 & 26.05 & 19 & 0.9635 & 21 & 28.17 & 21 & 0.9343 & 21 & 27.32 & 21 \\
\hline HPW 443 & 28.73 & 17 & 26.09 & 21 & 28.67 & 17 & 25.99 & 20 & 0.9750 & 19 & 28.51 & 19 & 0.9627 & 19 & 28.15 & 19 \\
\hline HPW 444 & 27.78 & 21 & 25.32 & 22 & 27.37 & 22 & 24.44 & 23 & 0.9388 & 22 & 27.45 & 22 & 0.9339 & 22 & 27.31 & 22 \\
\hline HPW 445 & 28.41 & 19 & 27.17 & 12 & 28.54 & 19 & 27.56 & 12 & 0.9781 & 18 & 28.60 & 18 & 0.9757 & 18 & 28.53 & 18 \\
\hline HPW 446 & 28.66 & 18 & 27.89 & 8 & 28.88 & 14 & 28.14 & 8 & 1.0033 & 10 & 29.34 & 10 & 0.9834 & 14 & 28.76 & 14 \\
\hline HPW 447 & 31.63 & 1 & 26.86 & 17 & 31.91 & 2 & 26.29 & 18 & 1.0578 & 3 & 30.93 & 3 & 1.0221 & 5 & 29.89 & 5 \\
\hline VL 2025 & 30.29 & 5 & 28.89 & 4 & 30.42 & 5 & 28.92 & 4 & 1.0447 & 5 & 30.55 & 5 & 1.0362 & 4 & 30.30 & 4 \\
\hline VL 2030 & 30.72 & 4 & 29.24 & 3 & 30.97 & 4 & 29.47 & 3 & 1.0562 & 4 & 30.88 & 4 & 1.0521 & 3 & 30.76 & 3 \\
\hline UP 2990 & 29.90 & 8 & 28.10 & 6 & 30.00 & 9 & 28.22 & 7 & 1.0218 & 9 & 29.88 & 9 & 1.0210 & 6 & 29.86 & 6 \\
\hline UP 2991 & 29.11 & 12 & 27.66 & 10 & 29.06 & 11 & 27.57 & 11 & 0.9992 & 11 & 29.22 & 11 & 0.9984 & 10 & 29.19 & 10 \\
\hline VL 907 & 29.61 & 9 & 28.48 & 5 & 29.78 & 10 & 28.79 & 5 & 1.0238 & 7 & 29.94 & 7 & 1.0183 & 9 & 29.78 & 9 \\
\hline HS 507 & 28.76 & 16 & 26.88 & 16 & 28.63 & 18 & 26.57 & 16 & 0.9809 & 16 & 28.68 & 16 & 0.9773 & 17 & 28.58 & 17 \\
\hline
\end{tabular}

BLUP ( average of values); HM-UP (Harmonic mean of BLUP); MHVG( Harmonic mean of the genotypic values); PRVG(Relative performance of genotypic values); GM (Overall average); MHPRVG ( harmonic mean of the relative performance of the predicted genotypic values); Rk (rank of genotypes) 
Table.6 Analytic measures of adaptability for wheat genotypes (2017-18)

\begin{tabular}{|c|c|c|c|c|c|c|c|c|c|c|c|c|c|c|c|c|}
\hline Genotype & BLUP & $\mathbf{R k}$ & HM-UP & $\mathbf{R k}$ & BLUE & $\mathbf{R k}$ & HM-UE & Rk & PRVG & $\mathbf{R k}$ & PRVG*GM & Rk & HPVRG & Rk & HPVRG*GM & Rk \\
\hline HPW 349 & 26.51 & 3 & 17.62 & 4 & 26.51 & 5 & 17.08 & 5 & 0.9943 & 4 & 26.24 & 4 & 0.9937 & 4 & 26.22 & 4 \\
\hline VL 907 & 25.91 & 6 & 19.27 & 1 & 26.24 & 7 & 19.65 & 1 & 1.0402 & 2 & 27.45 & 2 & 1.0222 & 2 & 26.97 & 2 \\
\hline HPW 441 & 26.46 & 4 & 18.21 & 3 & 27.15 & 2 & 18.59 & 3 & 1.0120 & 3 & 26.71 & 3 & 1.0112 & 3 & 26.68 & 3 \\
\hline HPW 442 & 26.70 & 2 & 17.24 & 6 & 26.78 & 4 & 16.93 & 6 & 0.9867 & 5 & 26.04 & 5 & 0.9811 & 5 & 25.89 & 5 \\
\hline HS 562 & 27.20 & 1 & 18.74 & 2 & 28.23 & 1 & 19.54 & 2 & 1.0414 & 1 & 27.48 & 1 & 1.0387 & 1 & 27.41 & 1 \\
\hline
\end{tabular}

BLUP ( average of values); HM-UP (Harmonic mean of BLUP); MHVG( Harmonic mean of the genotypic values); PRVG(Relative performance of genotypic values); GM (Overall average); MHPRVG ( harmonic mean of the relative performance of the predicted genotypic values); Rk (rank of genotypes)

Fig.1 Agro climatics zones for wheat cultivation in country

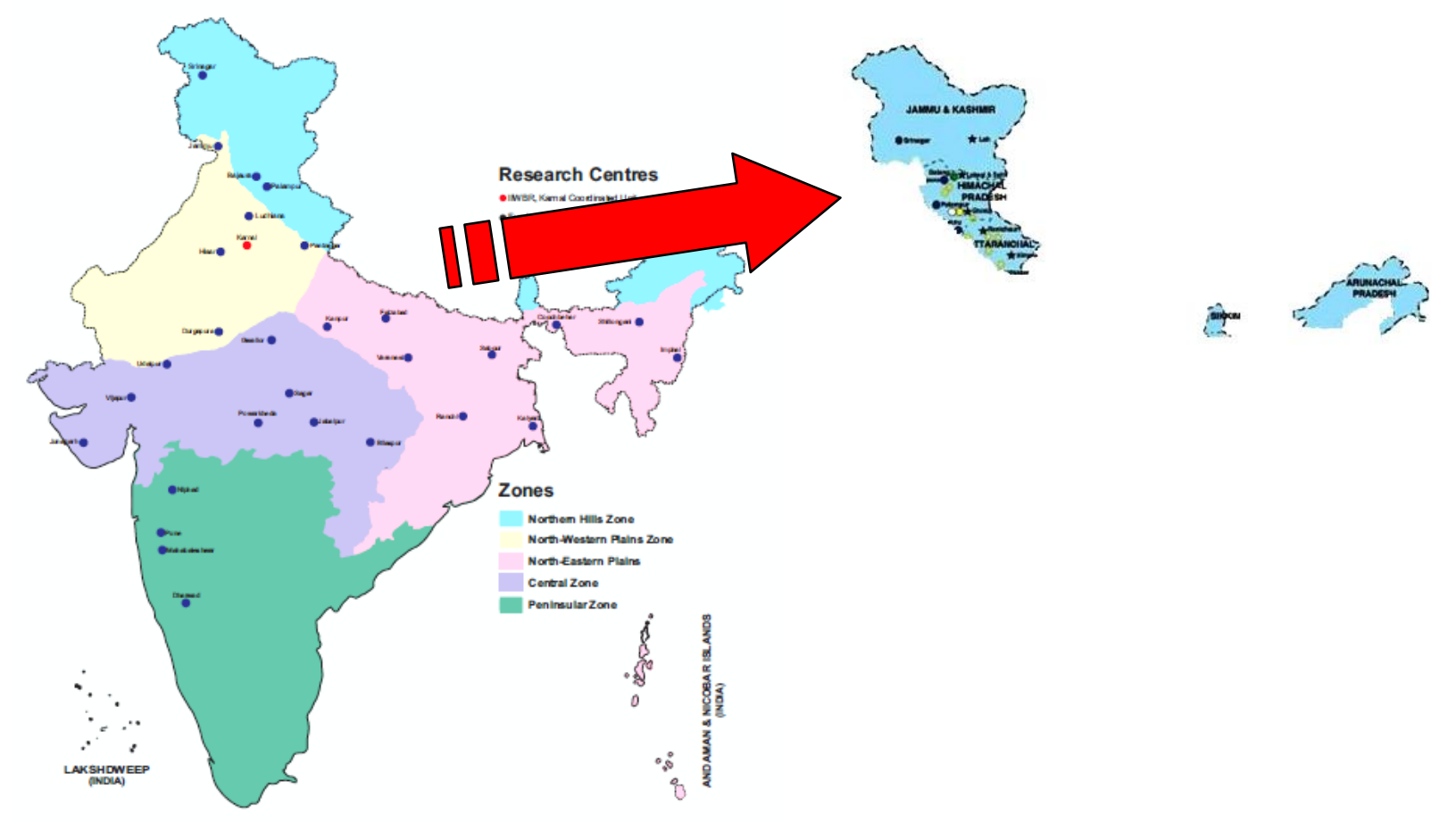


Fig.2 Average yield of wheat genotypes along with standard errors (2015-16)

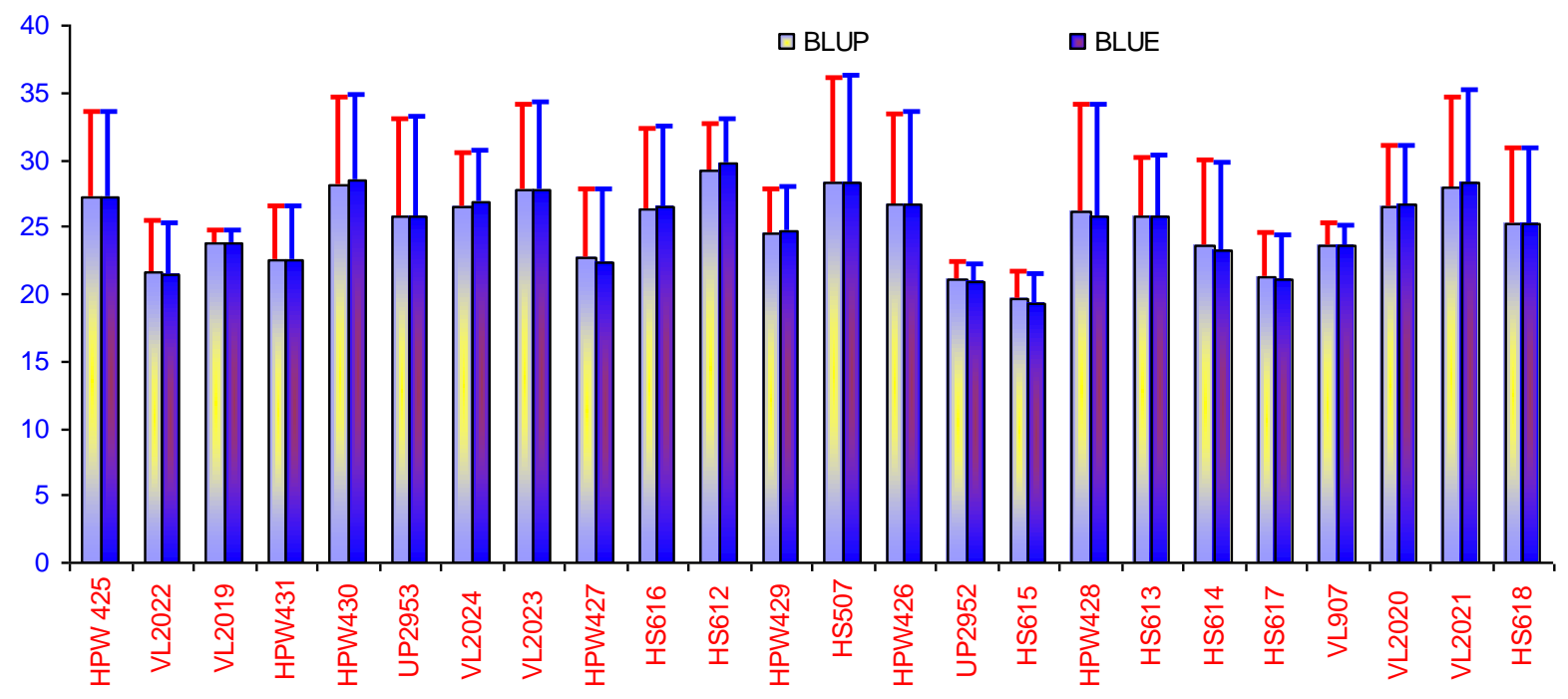

Fig.3 Average yield of wheat genotypes along with standard errors (2016-17)

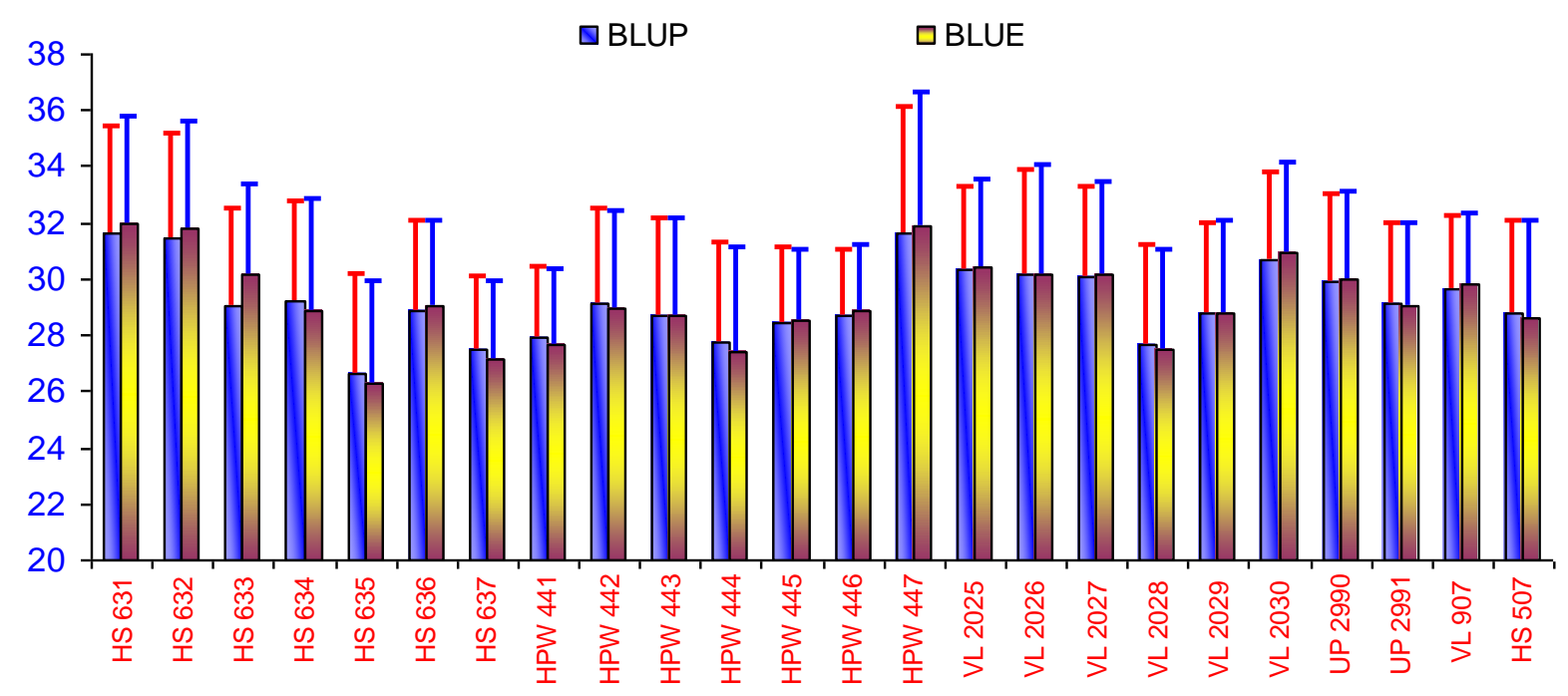


Fig.4 Average yield of wheat genotypes along with standard errors (2017-18)

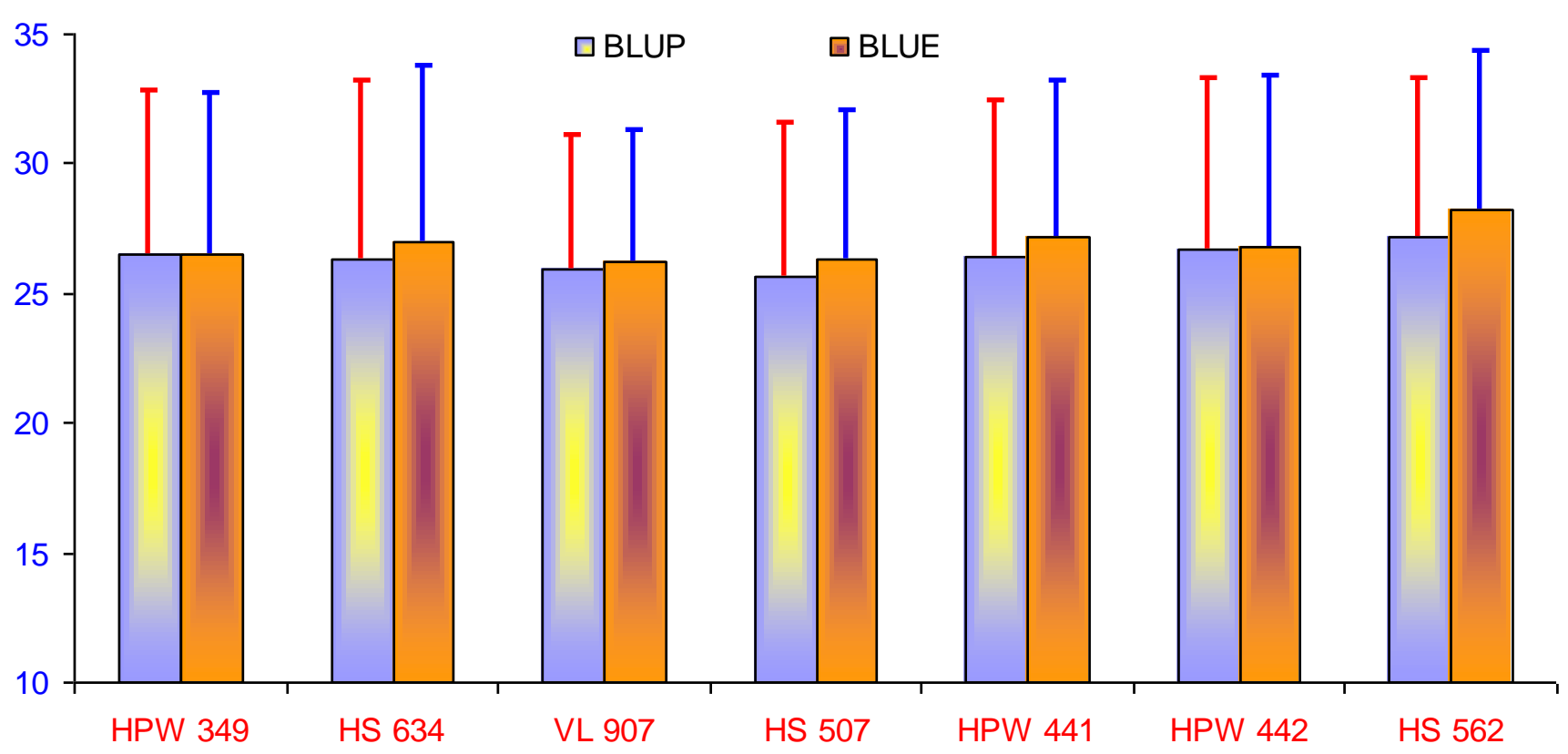


Fig.5 Biplot analysis of wheat genotypes vis-à-vis environments for irrigated timely sown trials (2015-16)

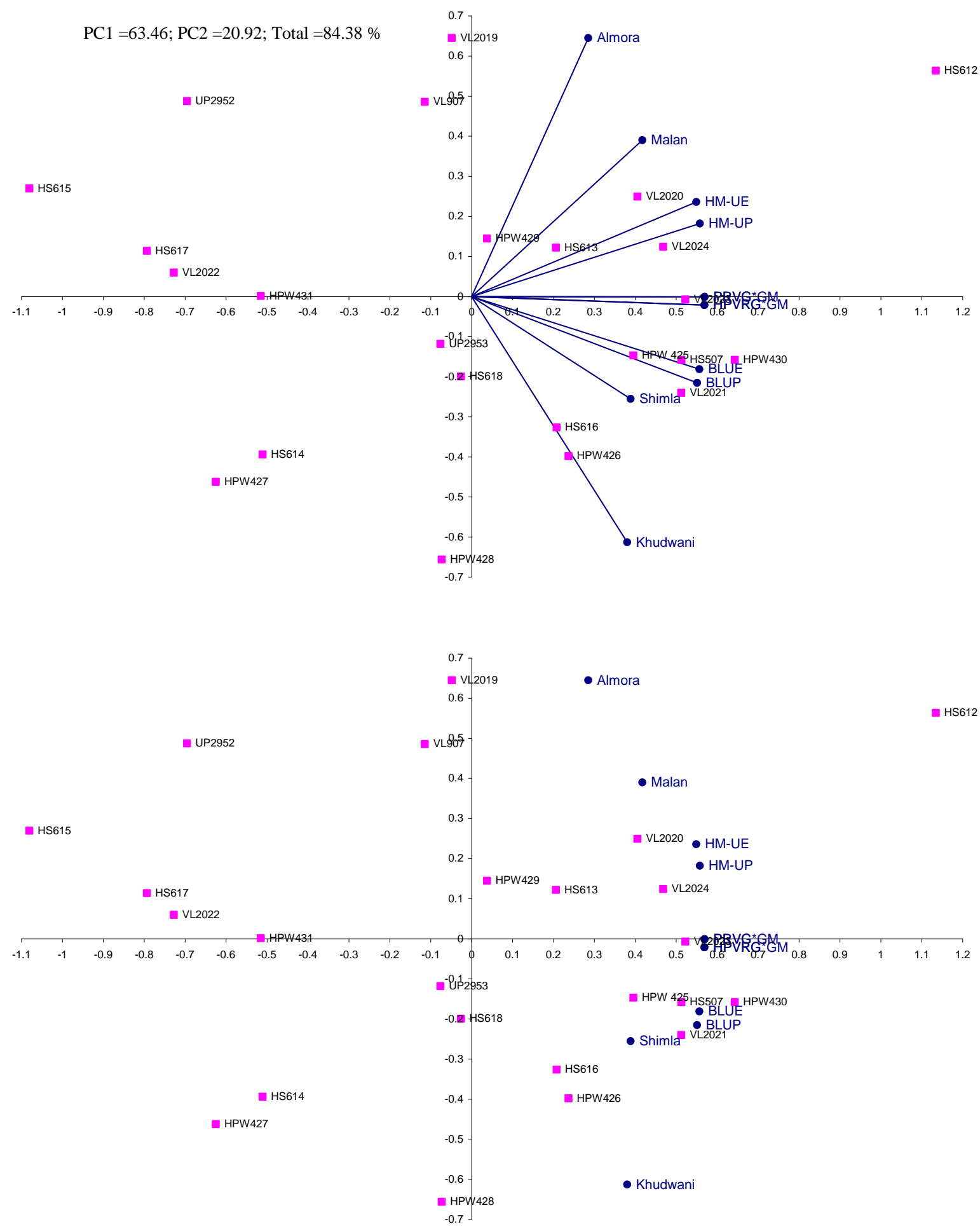


Fig.6 Biplot analysis of wheat genotypes vis-à-vis environments for irrigated timely sown trials (2016-17)
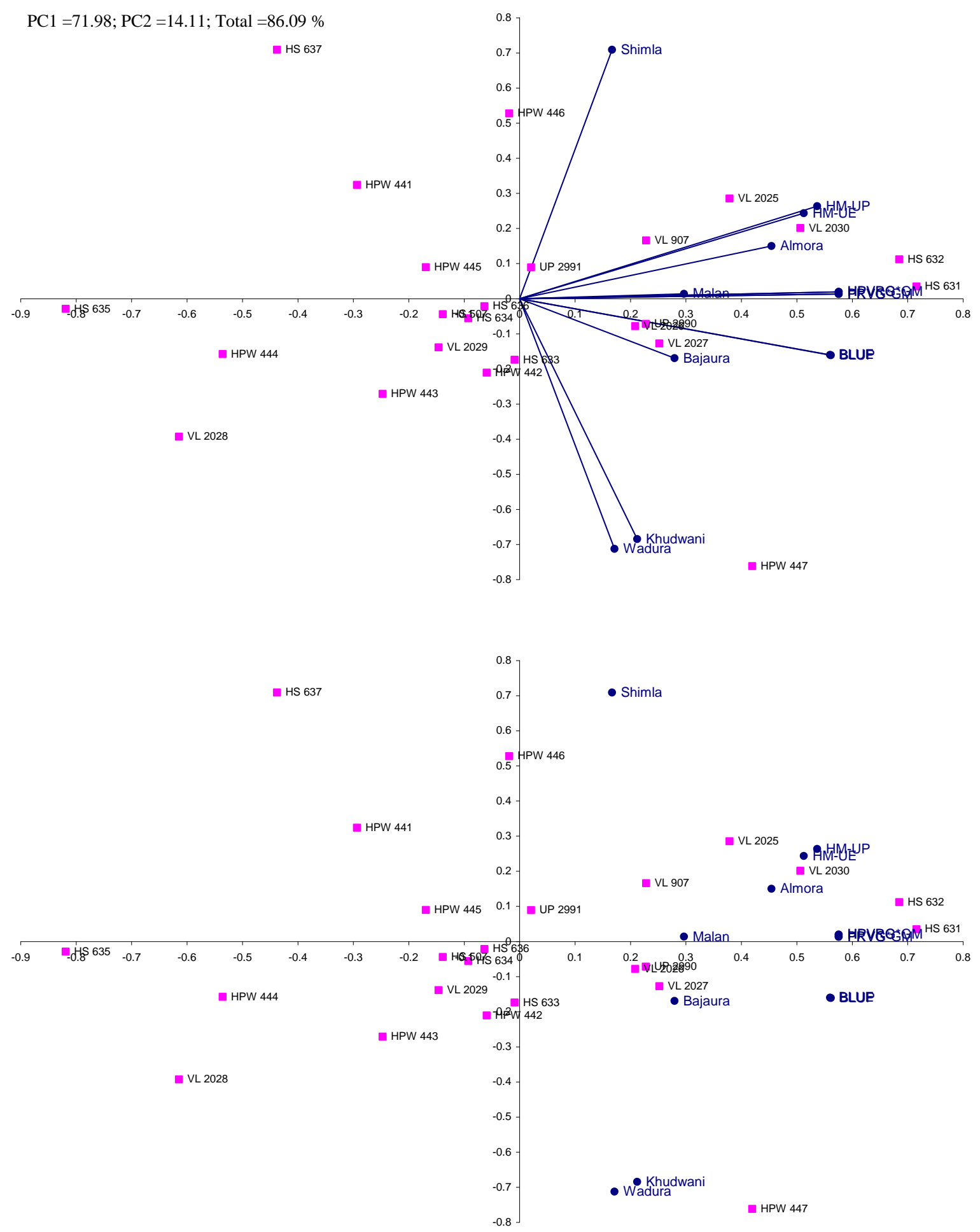
Fig.7 Biplot analysis of wheat genotypes vis-à-vis environments for irrigated timely sown trials (2017-18)

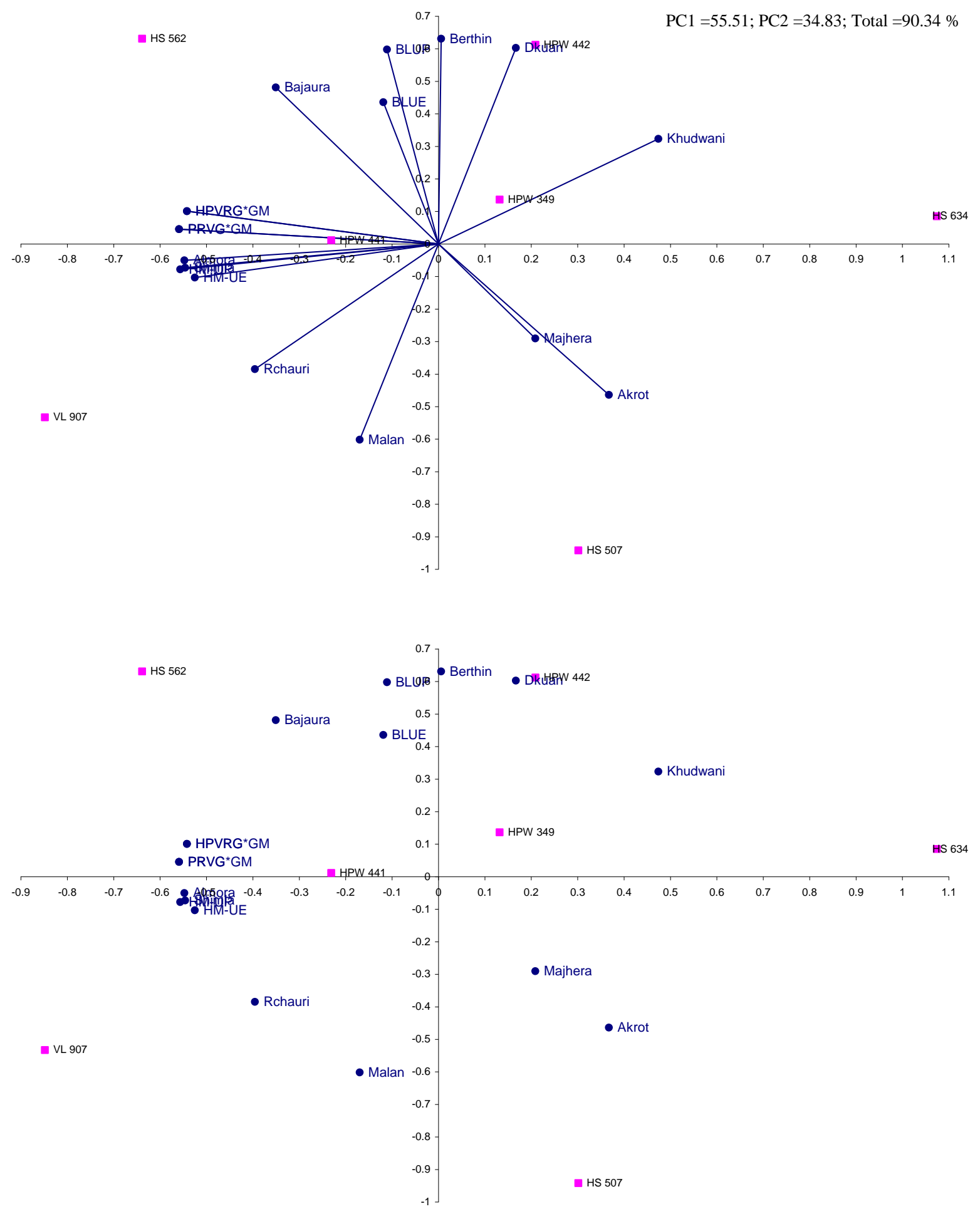


Malan with Almora, Shimla with Khudwani would show similar performance of genotypes as expressed acute angles among rays connecting these environments. Khudwani had an obtuse angle with Almora this would express different performance of genotypes for both locations.

The different analytic measures to estimate the adaptability of advanced wheat genotypes allow identifying and recommending efficient genotypes to the best environments to obtain increased yield (Mendes et al., 2012). Prime objective of wheat improvement is to identify genotypes with wider adaptations as well as good average yield even in heterogeneous environments.

Although, these conditions are not easy to satisfy, to increase wheat productivity at national level, it is very important to recommend wheat genotypes as per specific adaptations (Silveira et al., 2018). Proper exploitation of these specific positive interactions (Kleinknecht et al., 2011) in rational manner contributes to improve wheat productivity in Northern Hills Zone of the country.

\section{Acknowledgements}

Guidance of Dr J Crossa and financial support extended by Dr AK Joshi and Dr RP Singh, CIMMYT Mexico sincerely acknowledge by authors. Efforts of staff, working at various centers, are highly appreciated for field evaluation under coordinated system of wheat.

\section{References}

Burgueño J, Crossa J, Cornelius PL, Trethowan R, McLaren G and Krishnamachari A 2007. Modeling additive $\mathrm{x}$ environment and additive $\mathrm{x}$ additive $\mathrm{x}$ environment using genetic covariances of relatives of wheat genotypes. Crop Sci. 47: 311-320.

Burgueño J, Crossa J, Cotes JM, Vicente FS, Das B 2011. Prediction assessment of linear mixed models for multi environment trials. Crop Sci. 51: 944954.

Crespo-Herrera LA, Crossa J, Huerta-Espino J, Autrique E, Mondal S, Velu G. 2017. Genetic yield gains in CIMMYT's International Elite Spring Wheat Yield Trials by modeling the genotype $\times$ environment interaction. Crop Sci. 57:789-801.

Crossa J, Burgueno J, Cornelius PL, McLaren G, Trethowan R and Krishnamachari A 2006. Modeling genotype $\times$ environment interaction using additive genetic covariances of relatives for predicting breeding values of wheat genotypes. Crop Sci. 46:1722-1733.

Crossa J, Yang RC and Cornelius PL 2004. Studying crossover genotype $\times$ environment interaction using linearbilinear models and mixed models. $J$. Agric. Biol. Environ. Stat. 9:362-380.

Friesen LF, Brule-Babel AL, Crow GH and Rothenburger PA 2016. Mixed model and stability analysis of spring wheat genotype yield evaluation data from Manitoba, Canada. Can. J. Plant Sci. 96(2): 305-320.

Hernández M V, Ortiz-Monasterio I, PérezRodríguez $\mathrm{P}$, Montesinos-López $\mathrm{O} \mathrm{A}$, Montesinos-López A, Burgueño J and Crossa J 2019. Modeling Genotype $\times$ Environment Interaction Using a Factor Analytic Model of On-Farm Wheat Trials in the Yaqui Valley of Mexico Agron. J. 111:1-11.

Kelly A, Smith A, Eccleston J and Cullis B 2007. The accuracy of varietal selection using factor analytic models for multi environment plant breeding trials. Crop Sci. 47:1063-1070

Kleinknecht K, Laidig F, Piepho HP and Möhring J 2011. Best linear unbiased 
prediction (BLUP): Is it beneficial in official variety performance trials? Biuletyn Oceny Odmian 33:21-33.

Mendes F F, Guimarães L J M, Souza J C, Guimarães P E O, Pacheco C A P, Machado J R de A, Meirelles W F, Silva A R da \& Parentoni S 2012. Adaptability and stability of maize varieties using mixed model methodology. Crop Breeding and Applied Biotechnology. 12(2): 111117.

Meyer K 2009. Factor-analytic models for genotype $\mathrm{x}$ environment type problems and structured covariance matrices. Genet Sel Evol. 41: 21.

Nuvunga J J, Oliveira L A, Silva C P, Pamplona A KA, Silva A Q, Moura E G, Maleia M P, and Balestre M. 2018. Adaptability and stability of cotton cultivars (Gossypium hirsutum L. race latifolium $\mathrm{H}$.) using factor analytic model. Genet. Mol. Res. 17 (1):1-10.

Oliveira I, Atroch A, Costa Dias M, Guimarães L and Evaristo P 2017. Selection of corn cultivars for yield, stability, and adaptability in the state of Amazonas, Brazil. Pesq. agropec. bras., Brasília. 52(6):455-463.

Piepho HP, Möhring J, Melchinger AE and
Büchse A 2008. BLUP for phenotypic selection in plant breeding and variety testing. Euphytica. 161: 209-228.

Resende MDV.2007. Seleção genômica ampla (GWS) e modelos lineares mistos. In Resende MDV (ed) Matemática e estatística na análise de experimentos e no melhoramento genético. Embrapa Florestas, Colombo, p. 517-534.

Silveira D A, Bahry C A, Pricinotto L F, Nardino M, Carvalho I R, Souza V Q de 2018. Adaptability and stability of grain yield in soybean. Aust $J$ Crop Science. 12(05):717-725.

Smith A B and Cullis B R 2018. Plant breeding selection tools built on factor analytic mixed models for multienvironment trial data. Euphytica. 214(8):143-161.

Verardi CK, Resende MDZV, Costa RB and Gonçalves PS 2009. Adaptabilidade e estabilidade da produção de borracha e seleção em progênies de seringueira. Pesquisa Agropecuária Brasileira 44: 1277-1282.

Yan W and Kang M S 2003. GGE Biplot Analysis: A Graphical Tool for Breeders, Geneticists, and Agronomists. CRC Press. 228p.

\section{How to cite this article:}

Ajay Verma, R. Chatrath and Singh, G. P. 2019. Analytic Measures for Adaptability of Wheat Genotypes for Northern Hills Zone of Country by Mixed Model Approach. Int.J.Curr.Microbiol.App.Sci. 8(10): 43-60. doi: https://doi.org/10.20546/ijcmas.2019.810.006 